\title{
Evaluation of remuneration preferences of knowledge workers
}

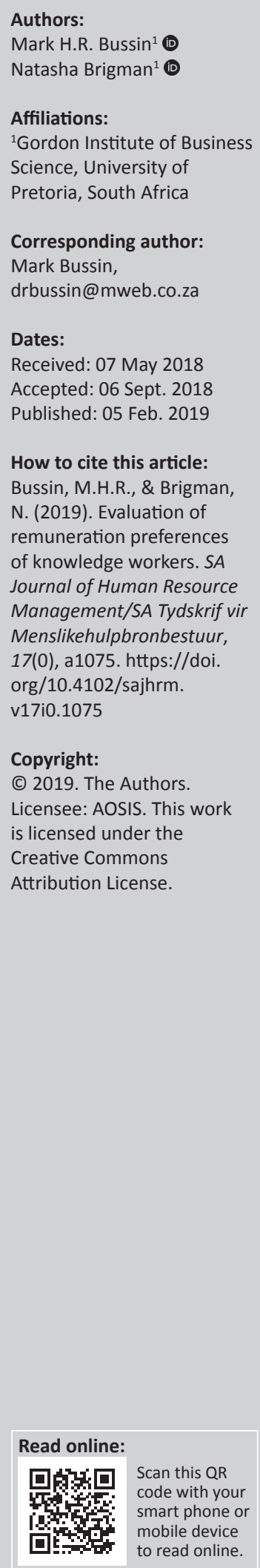

Orientation: This research evaluates the remuneration preferences of knowledge workers as a retention strategy in an integrated international energy and chemical company, using the WorldatWork Total Rewards Model.

Research purpose: Organisations may benefit from understanding their employees' preferential remuneration benefits, in particular, knowledge workers as a scare skill requiring specific retention strategies.

Motivation for the study: To understand the remuneration preferences for the retention of a group of knowledge workers within a large organisation based in South Africa. The research is necessary within organisations in South Africa impacted by scarce skills and a need to attract and retain knowledge workers. If remuneration preferences are not considered as part of retention, there is a risk knowledge workers may leave for preferential opportunities.

Research approach/design and method: A total of 199 employees from a group of 1229 voluntarily participated in the survey. An electronic-based questionnaire was developed from the WorldatWork rewards model. The results from the surveys were analysed with descriptive statistics and inferential statistics.

Main findings: No significance in reward strategies was found for age, level of performance or number of years of service. There was also no significant difference between the knowledge workers number of years of service and their intention to remain with the organisation. There was a significance in gender for benefits, flexibility and performance development preferences.

Practical/managerial implications: The development of retention strategies should consider reward preferences of male and female employees.

Contribution/value-add: Knowledge workers' reward preferences do not differ on demographic variables, except gender. This contradicts some literature in the area.

\section{Introduction \\ Key focus of the study}

The right total reward strategy can deliver the right amount to the right people at the right time, for the right reasons (Smit, 2013, p. 1).

The context of employment is continuously changing with both demographic and economic pressures which include increasing life expectancy, declining birth rates, the higher flexibility of human capital to relocate through globalisation and the shift towards knowledge-based economies (Tatoglu, Glaister, \& Demirbag, 2016). As globalisation continues to increase, the talent available to organisations will also increase. However, the ability to attract, retain and motivate this talent will become difficult because of the increased turnover costs which comprise loss of corporate memory, productivity and intellectual and social capital. There are different costs associated with losing talented employees (Schlechter, Thompson, \& Bussin, 2014c). The direct costs include the cost of a new recruit, lost time, recruiting, interviewing, onboarding and the onboarding of the new employee. Costs for losing an employee can be up to 2.5 times the annual salary paid for the job. The indirect financial costs include work disruptions, loss of knowledge, productivity, customers, mentors and even increased employee turnover (Schlechter et al., 2014c). 


\section{Background of the study}

Retaining knowledgeable employees is vital to the continual success of an organisation (Balakrishnan \& Vijayalakshmi, 2014). Organisations struggle to compete effectively to be the employer of choice (Balakrishnan \& Vijayalakshmi, 2014):

Employee retention is more than rivalling your competition with higher wages. It's about creating a work environment that nurtures diversity and mutual trust, providing challenging career opportunities, and treating people with respect and appreciation. (p. 69)

Boston Consulting Group estimates that there will be a worldwide shortage of knowledge workers of approximately 60 million by 2020 (Pobst, 2014). Employers are forced to compete to gain the talent and skills that are required to accomplish an organisation's strategic objectives. An excess supply of labour is no longer available to camouflage ineffective human resource strategies (Dawn \& Biswas, 2013).

South Africa is experiencing a skills crisis in general and retaining knowledge workers is difficult because of their unique attributes. This 'scarcity of skills stimulates the open competition for talent and drives turnover higher' (Khoele \& Daya, 2014, p. 5). A lack of an inclusive environment and obstacles for advancement has been shown to increase the turnover rate (Khoele \& Daya, 2014).

\section{Trends from the research literature}

Knowledge workers deal with complex problems where their daily tasks are unpredictable, multidisciplinary and not usually a task that is repetitive (Jayasingam, Govindasamy, \& Singh, 2016). This type of job requires the knowledge worker to utilise their mental abilities as their work has limited structure and cannot necessarily be standardised. Knowledge workers have also been described as the workers who apply theoretical and analytical knowledge they have acquired through formal education to produce new products and services (Jayasingam et al., 2016). Their higher degree of expertise shifts the bargaining power in their favour as they seek less dependence on their employer and they can seek employment elsewhere. The harsh reality is that knowledge workers leave results in loss of organisational knowledge that can be highly costly to an organisation especially if any employee is highly skilled and talented (Jayasingam et al., 2016).

Retaining knowledge workers is vastly different from traditional workers as they do not seek lifelong employment and security, rather they seek skills development and advancement opportunities (Pobst, 2014). These types of employees are in demand as having their skills can improve an organisation's competitive edge (Pobst, 2014). Retaining employees is not about updating compensation structures and having salaries higher than in the market. Having money-only incentives is expensive and could potentially not get the desired result (Bryant \& Allen, 2013).

\section{Research objectives and problem statement}

In an ideal situation, organisations should fully understand the needs of their employees in terms of remuneration preferences. Organisations should understand if their target type of employees would move jobs based on purely monetary compensation or do they prefer additional benefits such as flexible working arrangements, safety and security at the workplace, a work-life balance, recognition, personal development or various other remuneration options. This is important particularly to retain knowledge workers as the cost associated with replacing this knowledge far outweighs the cost of retaining them. The problem is that in reality organisations do not necessarily understand what remuneration preferences are, that are valued by employees. With the increased move towards globalisation, organisations no longer only face a threat of their knowledge workers moving within the region they operate in, instead they now compete for knowledge workers globally.

There were mixed results regarding the knowledge workers' remuneration preferences in the literature review by Pobst (2014) and Bryant and Allen (2013). In this research, the total rewards model that consists of both financial and non-financial components was used to test remuneration preferences of the knowledge worker sample within the international energy and chemical companies based in South Africa. From the literature review, it was discussed that both financial and nonfinancial rewards affect the retention of employees. Some studies showed that knowledge workers have a preference of talent development versus compensation (Khoele \& Daya, 2014). Some studies have shown that the preferred reward for employees is compensation. A questionnaire was developed to understand knowledge workers' remuneration preferences. In the questionnaire, respondents were questioned on each of the total rewards pillars:

- compensation

- benefits

- work-life effectiveness

- recognition

- performance management

- development and career opportunities.

The following hypotheses were developed from the literature: Hypothesis 1: Knowledge workers rate rewards differently based on their age.

Hypothesis 2: High-performing knowledge workers (performance rating excellent performer E) value rewards differently from lower performing knowledge workers (full performer F).

The literature review pointed to an interesting result that the longer an employee remains with an organisation, the less likely he or she is to leave the organisation (Jayasingam et al., 2016). This could be attributed to many factors, including their commitment to the organisation, their family commitments, the lack of jobs available in the market and various other factors (Jayasingam et al., 2016). For this study, we can measure the number of years the employee has worked for the organisation versus how many years they 
intend to continue working for the organisation. The exact reason for why they have chosen to stay would not be known. This resulted in the following hypothesis:

Hypothesis 3: Knowledge workers working at the same organisation for a long period of time rate their preference to remain with the organisation differently compared to knowledge workers with shorter service.

Research conducted by Khoele and Daya (2014) indicated that the turnover rate is higher with younger employees within an organisation compared to older employees. Some of the research alluded to the fact that older employees prefer stability, especially if they are closer to retirement so that they would be less inclined to leave the organisation. The literature also showed that younger employees are more focused on their career development and are willing to move between organisations to get the development they seek (Khoele \& Daya, 2014). The following hypothesis was developed:

Hypothesis 4: Younger age groups of knowledge workers differ in preference to leave the organisation compared to older knowledge workers.

Many studies showed the difference between reward preferences for men and women. One of the studies showed that more educated women tended to follow the same turnover pattern as men (Wöcke \& Heymann, 2012). There could be many reasons for the difference in rewards preferences from woman requiring more work-life effectiveness because of family commitments, female employees experiencing the 'glass ceiling' in the organisation therefore choosing more development rewards or a host of other reasons. This study will determine their preference and not necessarily why this is their preference:

Hypothesis 5: The total rewards preferences will differ between male and female knowledge workers.

\section{Potential value-add of the research}

An organisation that offers attractive remuneration packages to employees shows their employees that they do matter to the organisation, which consequently enhances their emotional bond with the organisation (Coetzee, Mitonga-Monga, \& Swart, 2014, p. 7).

Research of this nature is beneficial to organisations within South Africa as it is essential to retain knowledge workers. If ineffective retention and reward strategies are in place, there is a risk that knowledge workers will leave for preferential opportunities elsewhere which will ultimately be detrimental for the company, and possibly the future economic growth and development of South Africa (Theron, Barkhuizen, \& Plessis, 2014). Understanding how to incentivise and reward employees via the total reward factor model will retain knowledge workers and increase the attractiveness of working at the organisation. Various studies on the total rewards factors have been conducted in many different fields, but none has been conducted particularly in a large South African international energy and chemicals company.
This study will provide information for large companies such as this to ideally combine the total rewards factors to attract and retain knowledge workers.

\section{What will follow?}

This article will document a literature review defining the WorldatWork Total Rewards Model, knowledge workers, remuneration, turnover, retention and talent management to fully understand the scope of this study. The research methodology describing the sample, quantitative analysis to be performed and sample questionnaire will be discussed. Finally, the report will end with the survey analysis and discussion, conclusion and limitations and assumptions of this article.

\section{Synthesis and critical evaluation of the literature}

Knowledge workers can be defined as employees who have specialty knowledge within their area of expertise and by applying this knowledge, they can benefit the organisation in making informed decisions on complex matters (Jayasingam et al., 2016). Theory on the knowledge-based view and information economics indicated that knowledge workers are actually tangible assets, which are strategically important resources that facilitate the establishment of a competitive advantage (Jayasingam et al., 2016). Knowledge workers of the 21st century display different characteristics compared to their counterparts of the previous century. These workers display high levels of mobility, realise that their skills are highly demanded and do not aim to have a job for a lifetime. This change in behaviour greatly impacts the way in which retention needs to be managed. The study conducted by Khoele and Daya (2014) describes this change as 'moving from tending a dam to managing a river: the aim is not to prevent water from flowing, but to control its direction and speed' (p. 2).

Knowledge workers continually search for development and advancement opportunities, lateral or upward, within their organisation. The research conducted by Khoele and Daya (2014) has clearly shown that knowledge workers will leave if they cannot advance within their organisations. Organisations that focus on fostering growth and development will have lower turnover rates. Information from exit interviews conducted show that respondents who had left because of their relationship with their manager cited lack of communication, no direction or feedback and lack of agreement on their development (Khoele \& Daya, 2014).

There is limited research conducted on the reasons for why people stay or leave an organisation in developing countries (Theron et al., 2014). In the future, the demand for talented employees will far outweigh the supply at all levels within all industries. The following trends regarding retention of talent currently seen such as (Dawn \& Biswas, 2013):

- Approximately one-third of business failures can be attributed to poor hiring practice and the inability to attract and retain the correct talent. 
- The cost of replacing an employee is up to three times the cost of the person being replaced.

- There is a large cost associated with working around underperformers.

- The cost of not attracting and retaining good talent has side effects which cannot be quantified including decreased productivity, lower employee morale and reputational damage. (p. 44)

In a previous study investigating total rewards that retain staff, it is argued that employees who have the flexibility of a reward package aligned to their preference are more inclined to be loyal to the organisation (Pregnolato, Bussin, Schlechter, Town, \& Africa, 2017). South Africa needs to retain the knowledge and experience that have been cultivated within the country. According to research that was conducted on the impact of demographic variables on voluntary labour turnover in South Africa, it was found that various demographic variables such as age, race and gender influence individual turnover decisions (Wöcke \& Heymann, 2012). It was further found that the level of education influences mobility more than race does. With regard to gender affecting employee turnover, it was established that the turnover trends of highly educated women resemble the turnover of men far more than that of less educated women.

There is a forecasted shortage of skills in the next 15 years, particularly in the age bracket of 35-45 years. It is anticipated that the growth for demand in this bracket will increase by $25 \%$, whilst the supply of labour will decrease by $15 \%$ which results in a $40 \%$ shortfall of skills if no action is taken (Dawn \& Biswas, 2013). The ability to attract, retain and motivate this talent will become harder because of the increased turnover costs which comprise loss of corporate memory, productivity and intellectual and social capital. There are direct and indirect costs associated with losing talented employees (Schlechter et al., 2014c). The direct costs include the cost of replacing the employee, downtime, recruiting, interviewing, onboarding and the training and development of the new employee. Costs for losing an employee can be up to 2.5 times the annual salary paid for the job. The indirect financial costs include work disruptions, loss of knowledge, productivity, customers, mentors and even increased employee turnover (Schlechter et al., 2014c). Retaining key employees is critical to the long-term success of an organisation (Balakrishnan \& Vijayalakshmi, 2014).

The turnover of knowledge workers, especially in senior and management positions, has a detrimental effect on the productivity and profitability of an organisation. As stated by Khoele \& Daya, 2014:

High staff turnover is a cause for alarm, not only because of the costs associated with recruitment, selection and training, but also due to the increasing scarcity of experienced talent. (p. 1)

Knowledge workers represent an organisation's competitive advantage and the loss of these workers not only results in monetary and knowledge loss but also in the unavailability of experienced talent to replace them. South Africa is experiencing a skills crisis in general and retaining knowledge workers is difficult because of due to their unique attributes. This 'scarcity of skills stimulates the open competition for talent and drives turnover higher' (Khoele \& Daya, 2014, p. 5).

Globalisation has enabled knowledge workers' greater flexibility and higher mobility in the recent years; and in a survey conducted in large South African organisations, it was found that global mobility resulted in $21 \%$ of the total turnover (Khoele \& Daya, 2014). 'If SA is to prosper, highskilled individuals should be recruited and retained - not pushed to find opportunities elsewhere' and 'In the knowledge economy, knowledge elites are the bedrock of success. If we are to learn from history, cultivating them should be our number one priority' (Fourie, 2016, p. 4).

A reward is considered to be a significant tool to attract, stimulate motivation and ensure the retention of employees (Bussin, Van Rooy, \& Africa, 2012). The 'total rewards programme' includes rewards of monetary value and rewards that are non-monetary. Other benefits are included in non-monetary rewards. Employees may focus on rewards that are monetary-based but their behaviour is influenced by the non-monetary rewards.

From the study conducted on the retention of artisans within South Africa (Schlechter et al., 2014c), the following was noted:

- Employees build a deeper relationship with their employer with increased motivation, engagement and commitment when there are both financial and nonfinancial rewards.

- Increased flexibility also binds employees more strongly to the organisation as the organisation is able to cater for the employees' individual needs.

- Non-monetary rewards positively entice a psychological contract and leads to attracting and retaining talent. (p. 292)

A financial reward is made up of compensation and benefits. A study was conducted to test the effect of financial and non-financial remuneration on lecturers' performance and professionalism in Asia (Idris, Hamzah, Sudirman, \& Hamid, 2017). The results of the study showed that both financial and non-financial remuneration had a significant impact on the lecturers' professionalism. The study further showed that financial compensation had a positive effect on the lecturers' performance but non-financial compensation did not (Idris et al., 2017). So, the lecturers' performance was only influenced by financial compensation but their behaviour was affected by both financial and non-financial compensation.

Non-financial reward is made up of work-life effectiveness, recognition and performance management. A study conducted evaluating the impact of family and work-life balance on the performance of Spanish-listed companies showed that introducing work-life balance practices into an organisation 
benefits the organisation in terms of talent retention, higher employee engagement, higher productivity, lower costs and overall better business results (Benito-Osorio, MunozAguando, \& Villar, 2014).

Recognition can be described as the acknowledgement of employee actions, efforts, behaviour and performance both formal and informal. It is a part of the non-financial compensation that can be provided to employees and includes recognising achievements, promotion opportunities and providing development (Idris et al., 2017). A survey conducted by Idris et al. (2017) on various rewards found that employees regarded non-financial rewards higher than financial rewards.

Performance management is the alignment of organisational, team and individual goals to meet the business objectives. It is the establishment of expectations, skills, assessment and feedback and improvement. Performance feedback has been shown to significantly improve performance (Idris et al., 2017).

It was also found that demographic variables such as gender, race and age had no significant impact on the outcome of this result. From this research, it shows that job attractiveness for knowledge workers is directly linked to financial rewards, specifically remuneration or compensation (Schlechter, Hung, \& Bussin, 2014b). The total rewards model was used in this evaluation to determine the most preferred reward for knowledge workers. The ranking from this study was in order of preference: remuneration and benefits, work-life balance and learning and career advancement (Schlechter et al., 2014b).

South Africa is facing a greater problem of employee turnover because of the low supply of knowledge workers as a result of increased emigration and the lower standards of education. The Employment Equity Report in 2004 indicated that the turnover rate between races significantly differed. White male employees turned over at a rate of $9.35 \%$ compared to Africans, men and women, at $29.8 \%$ and other previously disadvantaged groups ranking at $14.1 \%$. This result may potentially be the result of the Employment Equity Act of 1998 as organisations are recruiting to meet the legislation. It was further found that this legislation had significant impacts on the psychological contracts of all groups with regard to faithfulness and career progression. African male managers were found to have the highest turnover rate because of the demand for them in the South African market as the legislation made them a wanted commodity (Wöcke \& Heymann, 2012).

Employee retention is composed of a number of structured activities, which results in attracting employees, especially talented employees, to stay with the organisation (Schlechter et al., 2014b). Crucial retention factors combined with a well-defined human resource planning, recruitment and selection process are required to ensure that the organisation has a functioning retention strategy.

\section{Research design \\ Research approach}

The research methodology followed was a quantitative method to reach the head-office-based population of approximately 1229 people in a junior management role and higher within a large integrated international energy and chemical companies based in South Africa. A total of 199 volunteered to participate. Primary data were sourced from electronic questionnaires. Analysis was undertaken using descriptive statistics and factor analysis.

\section{Research method}

\section{Research participants}

The participants in this study were 199 employees who volunteered to complete the survey. These employees were all based in the South African head office and all performed a role category from a junior management level to higher. As all of the employees are in a junior management role category or higher, these employees are considered as knowledge workers. There were no restrictions placed on the age of the participants or their number of years of service within the organisation.

The unit of analysis was a group of employees who are knowledge workers within the head office of a SouthAfrican-based company. All of these employees were from different business operating entities within the company and they were regarded as knowledge workers. Non-probability sampling was utilised as the researcher had no process to ensure that each part of the population could be present in the sample (Saunders \& Lewis, 2012). Convenience sampling was used as the population was readily available to the researcher. Participants were therefore selected via convenience non-probability sampling for this research.

\section{Measuring instruments}

A structured questionnaire was pre-developed from the information gathered in the literature survey. Ratings were based on a five-point Likert-type scale, where 1 is extremely negative and 5 is extremely positive. The questionnaire was focused around the WorldatWork total reward strategy model. Biographical information such as age, gender, highest academic qualification, level of work, race, job level, number of years with the company, number of years foreseen at the company and family status was requested.

\section{Research procedure}

The questionnaire was distributed to employees in the organisation electronically. A total of 199 people responded and all questionnaires were kept confidential. A pilot questionnaire was performed with ten employees within Sasol to ensure that the questionnaire was understandable. These participants are not included in the 199 respondents. 


\section{Statistical analysis}

The results from the surveys were analysed via descriptive statistics; frequencies were analysed together with inferential statistics. A Cronbach's alpha analysis and tests for significant difference were performed.

\section{Results}

An online survey was sent out to 1229 knowledge workers based at the head office of an international integrated energy and chemicals company. A total of 199 responses were received. The description of the sample is outlined in this section.

As a five-point Likert scale was used to measure the respondents' level of importance for each of the areas in this study, a Cronbach's alpha analysis was used to measure the internal consistency of the data and if the scale was reliable (see Table 1). The Cronbach's alpha measures the items in each of the categories that are ultimately measuring the same underlying dimension. A Cronbach's alpha was performed on each of the reward categories and on the financial and non-financial rewards.

\section{Statistical results per hypothesis}

\section{Hypothesis 1}

An Analysis of Variance (ANOVA) test for differences was performed to determine if there was a significant difference in knowledge workers' preferences for rewards based on their age (see Table 2). A one-way ANOVA analysis was performed where the independent variable was the knowledge workers' age and the dependent variable was all the financial and non-financial rewards. The $p$-value was less than 0.05 and therefore significant. This sample did not have equal variances; therefore, it violated the assumption

TABLE 1: Cronbach's alpha analysis.

\begin{tabular}{ll}
\hline Category & Cronbach's alpha \\
\hline Compensation & Good - Cronbach's alpha 0.784 $>0.65$ \\
Benefits & Good - Cronbach's alpha 0.810 $>0.65$ \\
Work-life balance & Good - Cronbach's alpha 0.686 >0.65 \\
$\begin{array}{l}\text { Performance management and recognition } \\
\text { Development and career opportunities }\end{array}$ & Bad - 0.583 construct was discarded \\
$\begin{array}{l}\text { Financial rewards (compensation and benefits) } \\
\begin{array}{l}\text { Non-financial rewards (work-life balance, } \\
\text { performance management and recognition } \\
\text { and development and career opportunities) }\end{array}\end{array}$ & Good - Cronbach's alpha $0.835>0.65$ \\
\hline
\end{tabular}

TABLE 2: Description data of sample - Age (years).

\begin{tabular}{lc}
\hline Range & Participants \\
\hline$<29$ & 10 \\
$30-35$ & 44 \\
$36-39$ & 32 \\
$40-45$ & 46 \\
$46-49$ & 33 \\
$50-55$ & 19 \\
$56-59$ & 13 \\
$60>$ & 2 \\
\hline Total & 199 \\
\hline
\end{tabular}

Mean, 41.7; standard deviation, 8.2; minimum, 26; maximum, 62. of homogeneity. The Games-Howell post-hoc analysis was performed. There was no significant difference in rewards preferences based on the knowledge workers' age. This was in line with Schlechter et al. (2014b) where it was also found that demographic variables such as gender, race and age had no significant impact on the outcome of this result. This result is in contrast to the work conducted by Pregnolato et al. (2017), Wöcke and Heymann (2012) and Khoele and Daya (2014), where there was a significant deviation in rewards preferences noted at different ages.

\section{Hypothesis 2}

An independent test of differences was used to evaluate if there is a difference in rewards preference between highperforming knowledge workers versus lower performing knowledge workers. The independent variable performance of the knowledge work: higher performing (E) or lowperforming (F) (see Table 3). The dependent variable was their rewards preference which included financial and nonfinancial rewards. Levene's test for homogeneity of variances was checked to have a $p$-value of greater than 0.05 of the sample. In our sample, all of the variables have a $p$-value of greater than 0.05; therefore, the assumption of homogeneity of variances is valid. From the $t$-test for equality of means referring to the equal variances row, all of the $p$-values were greater than 0.05 ; therefore, there is no statistical significant difference at a $95 \%$ confidence level.

Therefore, from the analysis, there is no significant difference between rewards preferences of high-performing knowledge workers versus lower performing knowledge workers. The null hypothesis can be accepted. Performance therefore had no significant impact on the knowledge workers' rewards preferences.

\section{Hypothesis 3}

An ANOVA test for differences was performed to determine if there was a significant difference in knowledge workers' preferences for remaining with the organisation based on the number of years served at the organisation (see Table 4 and Table 5). A one-way ANOVA analysis was performed

TABLE 3: Descriptive sample data - Last merit rating at the organisation.

\begin{tabular}{lc}
\hline Category & Participants \\
\hline X (non-performer) & 2 \\
N (new performer) & 4 \\
D (developing performer) & 6 \\
F (full performer) & 135 \\
E (excellent performer) & 49 \\
Other & 3 \\
\hline Total & 199 \\
\hline
\end{tabular}

TABLE 4: Descriptive sample data - Number of years with the organisation.

\begin{tabular}{lc}
\hline Categories & Participants \\
\hline$<2$ years & 11 \\
$3-5$ years & 24 \\
$6-9$ years & 35 \\
$>10$ years & 129 \\
\hline Total & 199 \\
\hline
\end{tabular}


TABLE 5: Descriptive sample data - Length of time you intend to continue working for this organisation.

\begin{tabular}{lc}
\hline Category & Participants \\
\hline At most 1 year & 24 \\
At most 2 years & 30 \\
At most 5 years & 36 \\
More than 5 years & 85 \\
Other & 23 \\
\hline Total & $\mathbf{1 9 8}$ \\
\hline
\end{tabular}

where the independent variable was the number of years with the organisation and the dependent variable was the participants' intended years to stay with the organisation. The $p$-value was greater than 0.05 and therefore not significant. This sample validated the assumption of homogeneity; therefore, Tukey's Honest Significant Difference (HSD) post hoc analysis was performed. There was no significant difference between the number of years a knowledge worker worked at an organisation and the number of years they intended to remain at the organisation. This is in contradiction to the study conducted by Khoele and Daya (2014) which showed that there is a correlation between the numbers of years an employee is with an organisation versus their retention. The longer an employee is with an organisation, the more likely they are to remain (Khoele \& Daya, 2014).

\section{Hypothesis 4}

An ANOVA test for differences was performed to determine if there was a significant difference of knowledge workers' preferences remaining with the organisation based on the participant's age (see Table 2). A one-way ANOVA analysis was performed where the independent variable was the knowledge workers' age and the dependent variable was the participants' intended years to stay with the organisation. The $p$-value was less than 0.05 and therefore significant. This sample did not have equal variances; therefore, it violated the assumption of homogeneity. The Games-Howell post-hoc analysis was performed. There was no significant difference in intention to stay with the organisation dependent on the knowledge workers' age. This is contradictory to many research studies which have shown that the age of employees has an impact on employee commitment, job embeddedness, employee's psychological contract and turnover decision. The study conducted also indicated that younger employees are more eager to leave (Wöcke \& Heymann, 2012). Age was shown in some research to have an impact on retention and turnover with younger employees tending to leave whilst older employees stay (Khoele \& Daya, 2014).

\section{Hypothesis $\mathbf{5}$}

An independent test of differences was used to evaluate if there is a difference in rewards preference between male and female knowledge workers. The independent variable was the knowledge workers' gender, male or female (see Table 6). The dependent variable was their rewards preference which included financial and non-financial rewards. From the analysis, there was a significant difference for all benefits (pension fund, medical allowance, car allowance, cell phone allowance, personal safety, on-site
TABLE 6: Description data of sample - Gender.

\begin{tabular}{lc}
\hline Sample & Participants \\
\hline Male & 115 \\
Female & 84 \\
\hline Total & $\mathbf{1 9 9}$ \\
\hline
\end{tabular}

canteen, on-site gym, on-site medical centre, on-site car wash and on-site crèche), flexibility (flexible hours, telecommuting and comfortable work environment) and performance development (performance support, personal development plan, succession planning, training and mentorship) preferences based on gender, men or women. This result is in agreement with the outcome found by Wöcke and Heymann (2012). There could be many reasons for the difference in rewards preferences from female employees requiring more work-life effectiveness because of family commitments, female employees experiencing the 'glass ceiling' in the organisation and therefore choosing more development rewards or a host of other reasons.

\section{Discussion}

'If SA is to prosper, high-skilled individuals should be recruited and retained - not pushed to find opportunities elsewhere' and 'In the knowledge economy, knowledge elites are the bedrock of success. If we are to learn from history, cultivating them should be our number one priority' (Fourie, 2016, p. 4).

The aim of this research was to understand the remuneration preferences for retention of a group of knowledge workers within a large organisation based in South Africa. If this research was not conducted in organisations within South Africa, knowledge workers will continue leaving for preferential opportunities elsewhere which will ultimately be detrimental for the future economic growth and development of South Africa. Understanding how to incentivise and reward employees via the total reward factor model will retain knowledge workers and increase the attractiveness of working at the organisation. Various studies on the total rewards factors have been conducted in many different fields, but none has been carried out particularly in a large South African international energy and chemicals company. This study was conducted to provide information for large companies such as this to ideally combine the total rewards factors to attract and retain knowledge workers.

In an ideal situation, organisations should fully understand the needs of their employees in terms of remuneration preferences. Organisations should understand if their target type of employees would move jobs based on purely monetary compensation or do they prefer additional benefits such as flexible working arrangements, safety and security at the workplace, a work-life balance, recognition, personal development or various other remuneration options. This is important particularly to retain knowledge workers as the cost associated with replacing this knowledge far outweighs the cost of retaining them. 
The problem is that organisations do not necessarily understand what remuneration preferences are valued by employees. In large organisations, investigating each individual's preference is a time-consuming task which may not be a priority to the organisation. This results in knowledge workers, who are vital to the organisations achievement of its strategy and maintaining its competitive edge, leaving because their reward preferences were not well understood.

In spite of the lack of sufficient knowledge workers in South Africa, organisations fail to recognise the importance in retaining the employees they have. If organisations continue to operate in this way, knowledge workers, who have much higher levels of mobility, have alternative options to either move to another organisation within South Africa or to leave South Africa. With the increased move towards globalisation, organisations no longer only face a threat of their knowledge workers moving within the region they operate instead they now compete for knowledge workers globally.

The WorldatWork Total Reward Programmes was used to evaluate the knowledge workers' rewards preferences via a quantitative research study. The 'total rewards programme' evaluated both rewards that are monetary-based and rewards that are non-monetary-based. Monetary rewards consist of basic and variable pay and the ownership of shares. Other benefits are included in non-monetary rewards.

For the quantitative analysis, the population size was 1229 employees from a junior management role and higher. A total of 199 employees voluntarily participated in the survey, all knowledge workers of various qualification levels and race as indicated by Table 7 and Table 8 . The sample was selected via convenience non-probability sampling. An electronic based questionnaire was developed from the WorldatWork rewards model. The results from the surveys were analysed via various statistical methods, that is, descriptive statistics and inferential statistics.

TABLE 7: Description data of sample - Race.

\begin{tabular}{lc}
\hline Sample & Participants \\
\hline African & 41 \\
Mixed race & 12 \\
Indian or Asian & 41 \\
Chinese & 1 \\
White & 101 \\
Other & 3 \\
\hline Total & $\mathbf{1 9 9}$ \\
\hline
\end{tabular}

TABLE 8: Descriptive sample data - Qualifications.

\begin{tabular}{lc}
\hline Category & Participants \\
\hline Grade 12 or lower & 0 \\
Certificate or diploma & 9 \\
Bachelor's degree & 55 \\
Postgraduate degree & 133 \\
Other & 2 \\
\hline Total & $\mathbf{1 9 9}$ \\
\hline
\end{tabular}

The main outcomes of the study were the following:

- There was no significant difference in rewards preferences based on the knowledge workers' age, level of performance or number of years of service.

- There was also no significant difference between the knowledge workers' number of years of service and their intention to remain with the organisation.

- From the analysis, there was a significant difference between male and female employees for benefits, flexibility and performance development preferences.

\section{Implications for management}

Organisations could benefit from understanding their employees' preferential remuneration benefits, in particular knowledge workers in order to retain them. Talent management systems need to be implemented in order to gain a competitive advantage through retaining valuable talent to execute the strategic intent of the organisation efficiently. With the skills shortage currently being experienced in South Africa especially in the leadership, senior management, technical and engineering fields, the demand for talent is high. Losing knowledgeable employees has a cost impact from both replacing the employee and attempting to rebuild the knowledge lost (Schlechter et al., 2014c).

Organisations need to have their retention and talent development strategies in place to retain knowledge workers. Understanding what remuneration preferences are favoured by knowledge workers could enable organisations to retain them. In a previous study investigating total rewards that retain states that employees who have the flexibility of a reward package aligned to their preference are more likely to remain with the organisation (Pregnolato et al., 2017).

Retaining employees is not about revamping compensation systems and paying considerably above market as throwing money alone at valuable employees can be a risky and expensive endeavour (Bryant \& Allen, 2013). South Africa is in dire need of retaining the knowledge and experience that have been cultivated within the country. Various studies have estimated that the replacement cost of losing a knowledgeable employee can potentially be up to $150 \%$ of the annual salary of the employee (Theron et al., 2014). The loss of individuals includes both psychological and intangible consequences such as a loss of knowledge, experience, disrupted productivity, lower morale and additional stress (Theron et al., 2014).

Globalisation has enabled knowledge workers' greater flexibility and higher mobility in the recent years, and in a survey conducted in large South African organisations, it was found that global mobility resulted in $21 \%$ of the total turnover (Khoele \& Daya, 2014).

The turnover of knowledge workers especially in senior and management positions has a detrimental effect on the 
productivity and profitability of an organisation. As stated by Khoele \& Daya, 2014:

High staff turnover is a cause for alarm, not only because of the costs associated with recruitment, selection and training, but also due to the increasing scarcity of experienced talent. (p. 1)

Knowledge workers represent an organisation's competitive advantage and the loss of these workers not only results in monetary and knowledge loss but also the unavailability of experienced talent to replace them. South Africa is experiencing a skills crisis in general and retaining knowledge workers is difficult because of their unique attributes. This 'scarcity of skills stimulates the open competition for talent and drives turnover higher' (Khoele \& Daya, 2014, p. 5)

In addition to the high cost of losing, an employee has other effects such as work disruptions, loss of valuable organisational knowledge, strategic knowledge, loss in productivity, loss of mentors, diminished diversity and turnover contagion most likely will occur (Bryant \& Allen, 2013; Schlechter, Faught, \& Bussin, 2014a).

Retaining key employees is critical to the long-term success of an organisation (Balakrishnan \& Vijayalakshmi, 2014). In addition to the losses that accompany the turnover of knowledgeable employees, South Africa is suffering from a major skills shortage especially in technical fields such as engineering (Rasool \& Botha, 2011). South Africa is losing a large number of its knowledge workers which will eventually disable the economy from competing globally (Coetzee et al., 2014; Rasool \& Botha, 2011). Employers are forced to compete to gain the talent and skills that are required to accomplish the organisations' strategic objectives. An excess supply of labour is no longer available to camouflage ineffective human resource strategies (Dawn \& Biswas, 2013):

- A 'one-size-fits-all' approach cannot be used to incentivise knowledge workers.

- There is a significant difference between reward preferences between the different genders and if the organisation wishes to increase the number of female representatives within its work force, these different needs will need to be actively addressed.

- Other research showed that age has a significant impact on the retention of knowledge workers. It was not evident amongst the sample of knowledge workers in this large organisation.

- Rewards preferences between high-performing knowledge workers and low-performing knowledge workers were shown to be statistically insignificant.

\section{Limitations of the research}

The research was undertaken in one organisation with a specific culture and processes. This may limit the generalisability of the findings to other organisations and other emerging markets. The research could have been complemented by qualitative research methods to understand the motivation and drivers of employees more deeply.

\section{Suggestions for future research}

There is limited research conducted on the reasons of why employees stay or leave an organisation in developing countries (Theron et al., 2014). In addition to research into retention in organisations, the connection to reward and the impact on other organisational features is necessary. For instance, the culture, leadership perception, more information on non-financial rewards may all impact the retention of knowledge workers. It would also be useful to undertake a post hoc analysis of knowledge workers who have left organisations to investigate their reasons of leaving, and compare this with current employees' perceptions. Further research could also compare the reward preferences of knowledge workers in developed countries versus developing countries.

\section{Conclusion}

There was no significant difference in rewards preferences based on the knowledge workers' age, level of performance or number of years of service. There was also no significant difference between the knowledge workers' number of years of service and their intention to remain with the organisation. From the analysis, it was found that there was a significant difference between male and female employees' preferences of benefits, flexibility and performance development. Knowledge workers' reward preferences differ based on demographic variables such as gender.

\section{Acknowledgements}

I acknowledge Mark H.R. Bussin (my supervisor), Ronel Nienaber for her assistance in attaining the sample data and my family members, Navash Brigman, Roshila Brigman and Sunjith Brigman, for their support.

\section{Competing interests}

The authors declare that they have no financial or personal relationships that may have inappropriately influenced them in writing this article.

\section{Authors' contributions}

N.B. was responsible for project design and analysis. M.H.R.B. made intellectual and conceptual contribution. N.B. and M.H.R.B. wrote the manuscript.

\section{References}

Balakrishnan, L., \& Vijayalakshmi, M. (2014). A study on retention strategy's followed by education institutions in retaining qualified employees. SIES Journal of Management, 10(1), 69-81.

Benito-Osorio, D., Munoz-Aguando, L., \& Villar, C. (2014). The impact of family and work-life balance policies on the performance of Spanish listed companies. Aims Management, 17(4), 214-236.

Bryant, P. C., \& Allen, D. G. (2013). Compensation, benefits and employee turnover: HR strategies for retaining top talent. Sage Publications, 45(3), 171-175. https:// doi.org/10.1177/0886368713494342

Bussin, M., \& Van Rooy, D. J. (2012). Total rewards strategy for a multi-generational workforce in a financial institution. SA Journal of Human Resource Management, 12(1), 1-11. https://doi.org/10.4102/sajhrm.v12i1.606 
Coetzee, M., Mitonga-Monga, J., \& Swart, B. (2014). Human resource practices as predictors of engineering staff's organisational commitment. SA Journal of Human Resource Management, October, 1-10. https://doi.org/10.4102/sajhrm.v12i1.604

Dawn, S. K., \& Biswas, S. (2013). Talent management: Designing strategies. Bi-Annual Journal of Asian School of Business Management, VI(II), 41-51.

Fourie, J. (2016). Highly skilled migrants do matter. Finweek, (November), 4. Retrieved from http://search.ebscohost.com/login.aspx?direct=true\&db=bth\&AN=119439 $636 \&$ site=ehost-live

Idris, M. H., Hamzah, D., Sudirman, I., \& Hamid, N. (2017). The relevance of financial and non-financial compensation on professionalism and lecturers performance: Evidence from Makassar Private Universities (Indonesia). Journal of Asian Development, 3(2), 162-180. https://doi.org/10.5296/jad.v3i2.11491

Jayasingam, S., Govindasamy, M., \& Garib Singh, S. K. (2016). Instilling affective commitment: Insights on what makes knowledge workers want to stay. Management Research Review, 39(3), 266-288. https://doi.org/10.1108/MRR03-2014-0060

Khoele, A., \& Daya, P. (2014). Investigating the turnover of middle and senior managers in the pharmaceutical industry in South Africa. SA Journal of Human Resource Management, 12(1), 1-10. https://doi.org/10.4102/sajhrm.v12i1.562

Pobst, G. F. (2014). Meeting the challenge of knowledge worker shortages with strategic talent management, American Journal of Management, 14, 62-67.

Pregnolato, M., Bussin, M. H. R., \& Schlechter, A. F. (2017). Total rewards that retain: A study of demographic preferences. SA Journal of Human Resource Management, 15, 1-10.

Rasool, F., \& Botha, C. J. (2011). The nature, extent and effect of skills shortages on skills migration in South Africa. SA Journal of Human Resource Management, July, 1-13. https://doi.org/10.4102/sajhrm.v9il.287
Saunders, M., \& Lewis, P. (2012). Doing research in business and management. Essex: England. Pearson.

Schlechter, A., Faught, C., \& Bussin, M. (2014a). Total rewards: A study of artisan attraction and retention within a South African context. SA Journal of Human Resource Management, 12(1), 1-15. http://doi.org/10.4102/sajhrm.v12i1.648

Schlechter, A., Hung, A., \& Bussin, M. (2014b). Understanding talent attraction: The influence of financial rewards elements on perceived job attractiveness. SA Journal of Human Resource Management, 12(1), 1-13. https://doi.org/ 10.4102/sajhrm.v12i1.647

Schlechter, A., Thompson, N. C., \& Bussin, M. (2014c). Attractiveness of non-financial rewards for prospective knowledge workers an experimental investigation, 37(3) 274-295. https://doi.org/10.1108/ER-06-2014-0077

Smit, W. A. (2013). Retention preferences from a multi-generation workforce perspective: The relationship between total rewards, perceived organisational support and perceived supervisor support. Thesis, Faculty of Economic and Management Sciences, University of Pretoria.

Tatoglu, E., Glaister, A. J., \& Demirbag, M. (2016). Talent management motives and practices in an emerging market: A comparison between MNEs and local firms. Journal of World Business, 51(2), 278-293. https://doi.org/10.1016/j. jwb.2015.11.001

Theron, M., Barkhuizen, N., \& Du Plessis, Y. (2014). Managing the academic talent void: Investigating factors in academic turnover and retention in South Africa. SA Journal of Industrial Psychology, 2011, 1-15. https://doi.org/10.4102/sajip. v40i1.1117

Wöcke, A. \& Heymann, M. (2012). Impact of demographic variables on voluntary labour turnover in South Africa. The International Journal of Human Resource Management, 23(16), 3479-3494. https://doi.org/10.1080/09585192.2011. 639028 